CLINICAL STUDY

\title{
Increased IGF 1 levels in relation to heart failure and cardiovascular mortality in an elderly population: impact of ACE inhibitors
}

\author{
Simona I Chisalita ${ }^{1,2}$, Ulf Dahlström ${ }^{3,4}$, Hans J Arnqvist ${ }^{2,5}$ and Urban Alehagen ${ }^{3,4}$ \\ ${ }^{1}$ Department of Acute Healthcare, County Council of Östergötland, Linköping S-581 85, Sweden, ${ }^{2}$ Division of Cell Biology, Department of Clinical and \\ Experimental Medicine and ${ }^{3}$ Division of Cardiovascular Medicine, Department of Medicine and Health Sciences, Faculty of Health Sciences, Linköping \\ University, Linköping, Sweden, ${ }^{4}$ Department of Cardiology UHL and ${ }^{5}$ Department of Endocrinology and Gastroenterology UHL, County Council of \\ Östergötland, Linköping, Sweden \\ (Correspondence should be addressed to S I Chisalita at Department of Acute Healthcare, County Council of Östergötland; Email: simona.chisalita@lio.se)
}

\begin{abstract}
Objective: There are conflicting results regarding the association of circulating IGF1 with cardiovascular (CV) morbidity and mortality. We assessed the relationship between IGF1 levels and heart failure (HF), ischemic heart disease (IHD), and CV mortality in an elderly population taking into account the possible impact of angiotensin converting enzyme (ACE) inhibitors.

Design and methods: A total of 851 persons aged 66-81 years, in a rural Swedish municipality, were subjected to medical history, clinical examination, electrocardiography, echocardiography, and fasting plasma samples. They were then followed for 8 years.

Results and conclusion: Patients on ACE inhibitors had higher IGF1 levels compared with those without ACE inhibitors. In patients on ACE inhibitors, higher IGF1 values were found in patients with an ejection fraction $(\mathrm{EF})<40 \%$ compared with $\mathrm{EF} \geq 40 \%$, in patients with higher proBNP levels in quartile 4 vs 1 , and in patients with IHD when compared to those without ACE inhibitors $(P<0.001)$. In patients without ACE inhibitors, no relationship was found between IGF1 levels and HF or IHD. In multivariate regression, only ACE inhibitors, ECG changes characteristic for IHD, and gender had a significant impact on IGF1. Patients with higher IGF1 levels in quintiles 4 and 5 compared to quintiles 1 and 2 had a 50\% higher risk for $\mathrm{CV}$ death $(P=0.03)$. This was significant after adjustment for wellknown CV risk factors and ACE inhibitors $(P=0.03)$.

Conclusions: Our results show that treatment with ACE inhibitors in an elderly population is associated with increased IGF1 levels, especially in patients with impaired cardiac function or IHD. High IGF1 levels tend to be associated with an increased risk for CV mortality.
\end{abstract}

European Journal of Endocrinology 165 891-898

\section{Introduction}

Cardiovascular (CV) disease is a major cause of morbidity and mortality in the western world. A number of studies have shown that insulin-like growth factor 1 (IGF1) is related to CV disease, but the mechanisms involved are still not clear (1-3). Both low and high levels of circulating IGF1 have been reported to be associated with increased mortality (4-6) as well as with cardiac failure (7). Protective $(1,8,9)$ as well as harmful $(5,10)$ effects of IGF1 on the CV system have been reported. In adults, IGF1 has anabolic effects on connective tissues, muscles, and heart $(11,12)$. It has been reported that infusion of IGF1 in healthy individuals has a positive inotropic effect (13) and improves left ventricular performance in those with heart failure (HF) (14).
It is conceivable that IGF1 plays a dual role in the vascular wall; stimulating nitric oxide $(\mathrm{NO})$ production in the intact endothelium thereby inhibiting smooth muscle cell proliferation, but may directly stimulate smooth muscle cell proliferation if the endothelium is damaged $(10,15,16)$. Angiotensin II is a potent inhibitor of local IGF1 expression, and it has therefore been suggested that angiotensin converting enzyme (ACE) inhibitors may enhance local IGF1 secretion (17). Indeed, treatment with ACE inhibitors, commonly used in patients with cardiac disorders, has been shown to moderately increase plasma IGF1 $(18,19)$.

By influencing IGF1 levels, ACE inhibitors could be a confounding factor in studies on IGF 1 and CV disease and mortality. In this observational study on an elderly population, we tested the hypothesis that there is an association between IGF 1 and cardiac function as well 
as between IGF1 and CV mortality considering the impact of ACE inhibitors.

\section{Research design and methods}

The study population has previously been described in detail (20). Briefly, a rural municipality with 10300 inhabitants situated in southeast Sweden was chosen. All individuals aged 66-81 years residing in the municipality were invited to participate in the study. Of the 1162 subjects, 851 (73.3\%) agreed to participate.

All participants (851 persons) were examined by experienced cardiologists. A medical history was taken, and a clinical examination, including weight and height, was performed. Functional class was assessed by the New York Heart Association (NYHA Class), and an electrocardiogram (ECG) and Doppler echocardiography were done. Blood pressure was measured to the nearest $5 \mathrm{mmHg}$, with the patient resting in the supine position. The study protocol was approved by the Ethics Review Board in Linköping.

\section{Blood samples and biochemical analysis}

Blood samples were obtained from fasting subjects after a resting period of $30 \mathrm{~min}$. The samples were collected in pre-chilled plastic tubes containing EDTA (Terumo EDTA K-3), placed on ice, and centrifuged at $3000 \mathrm{~g}$ for $10 \mathrm{~min}$ at $4{ }^{\circ} \mathrm{C}$. The samples were then immediately stored at $-70{ }^{\circ} \mathrm{C}$ pending analysis. Total plasma IGF1 was measured by a one-step ELISA after acid-ethanol extraction from its binding protein using a commercial kit (R\&D Systems, Minneapolis, MN, USA). The assay was performed according to the manufacturer's protocol. Interassay coefficients of variation were $10.9,5.9$, and $18.2 \%$ for high, medium, and low controls respectively. N-terminal proBNP (NT-proBNP) was measured using an electrochemiluminescence immunoassay (Elecsys 2010, Roche Diagnostics), first described by Karl et al. (21). The analytical range was 5-35 $000 \mathrm{ng} / \mathrm{l}(0.6-4130 \mathrm{pmol} / \mathrm{l})$. Total coefficients of variation was $4.8 \%$ at the level of $217 \mathrm{ng} / \mathrm{l}(26 \mathrm{pmol} / \mathrm{l}$; $n=70)$ and $2.1 \%$ at the level of $4261 \mathrm{ng} / \mathrm{l}(503 \mathrm{pmol} / \mathrm{l})$ at our laboratory.

\section{Doppler echocardiography}

Doppler echocardiography (Accuson XP-128c) was done in all patients in the left supine position. Both M-mode and two-dimensional methodologies were used. Left ventricular systolic function was determined semi-quantitatively, with the global systolic function classified as follows: normal (ejection fraction (EF) $\geq 50 \%$ ), mild impairment (EF 40-49\%), moderately impaired function (EF 30-40\%), and severely impaired function $(\mathrm{EF}<30 \%)$. The method has been validated against the modified Simpson algorithm $(22,23)$.

\section{Concomitant disease}

Diabetes mellitus was defined as a fasting plasma blood glucose concentration $\geq 7.0 \mathrm{mmol} / \mathrm{l}$, or current treatment for diabetes (diet, oral therapy, or insulin). Ischemic heart disease (IHD) was defined as a history of coronary artery disease (CAD), angina pectoris, treatment for angina pectoris, a verified myocardial infarction, coronary artery bypass surgery, percutaneous coronary intervention, and/or ECG changes characteristic for IHD (examined by three experienced cardiologists).

\section{Follow-up of included patients}

All patients were followed for 8 years $(7.9 \pm 2.6)$ and no patient was lost during this period. During the follow-up period, all patients received standard treatment according to clinical routines.

In all cases reported as dead, death certificates were obtained from the Swedish Central Population Register and information about cause of death and autopsy reports were analyzed by the authors. All autopsies had been performed at the University Hospital in Linköping. All-cause mortality and CV mortality were chosen as end points. CV mortality was defined as death caused by HF, fatal arrhythmia, sudden death, IHD, or cerebrovascular death as deduced from the autopsy report or death certificate issued by the physician in charge of the patient.

\section{Statistical analysis}

Data are presented as mean \pm s.D. For normally distributed variables, analysis was performed using Student's $t$-test. A multivariate regression analysis was used to assess the impact of gender, ACE inhibitors, ECG changes for IHD, CAD history, IHD, EF $<40 \%$, body mass index (BMI), creatinine, and NT proBNP on IGF1 levels. Survival analysis was performed using KaplanMeier survival curve analysis. A Cox proportional hazard regression analysis was performed to identify the weight of the individual risk variables for $\mathrm{CV}$ mortality. A $P$ value $<0.05$ was considered statistically significant. Data analysis was performed using commercially available statistical analysis software packages PASW Statistics version 18 (SPSS, Inc., Headquarters, Chicago, IL, USA).

\section{Results}

\section{Basic characteristics of patients in the study population}

Table 1 shows the baseline characteristics of the study population. Among the 851 participants, there were an almost equal number of women and men $(n=436$ vs 
Table 1 Population baseline characteristics.

\begin{tabular}{|c|c|c|c|c|}
\hline Variables & $\begin{array}{l}\text { Whole } \\
\text { population }\end{array}$ & Female & Male & $P$ values \\
\hline Total $(n)$ & 851 & 436 & 415 & \\
\hline \multicolumn{4}{|l|}{ History $(n(\%))$} & 0.002 \\
\hline Diabetes mellitus & $123(14.4)$ & $64(52.0)$ & $59(48.0)$ & 0.8 \\
\hline IHD & $157(18.4)$ & $68(43.3)$ & $89(56.7)$ & 0.03 \\
\hline ECG & $47(5.5)$ & $14(29.8)$ & $33(70.2)$ & 0.003 \\
\hline CAD & $127(14.9)$ & $60(47.3)$ & $67(52.7)$ & 0.3 \\
\hline NYHA I & $519(61.0)$ & $255(49.1)$ & $264(50.9)$ & 0.1 \\
\hline NYHA II & $266(31.2)$ & $146(54.8)$ & $120(45.1)$ & 0.1 \\
\hline NYHA III & $66(7.7)$ & $35(53.0)$ & $31(47.0)$ & 0.8 \\
\hline \multicolumn{5}{|l|}{ Clinical variables } \\
\hline Weight (mean \pm s.D.; kg) & $75.4 \pm 13.1$ & $71.4 \pm 1.4$ & $79.7 \pm 11.3$ & $<0.001$ \\
\hline Height (mean \pm S.D.; cm) & $168.1 \pm 10.5$ & $161.7 \pm 9.7$ & $174.8 \pm 6.2$ & $<0.001$ \\
\hline BMI (mean \pm s.D.; $\left.\mathrm{kg} / \mathrm{m}^{2}\right)$ & $26.6 \pm 4.2$ & $27.2 \pm 4.8$ & $26.1 \pm 3.4$ & $<0.001$ \\
\hline $\mathrm{EF} \geq 40 \%(n(\%))$ & $795(93.4)$ & $413(51.9)$ & $382(44.1)$ & 0.1 \\
\hline $\mathrm{EF}<40 \%(n(\%))$ & $42(5.0)$ & $12(28.6)$ & $30(71.4)$ & 0.003 \\
\hline \multicolumn{5}{|l|}{ Treatment $(n(\%))$} \\
\hline ACE inhibitor & $173(20.3)$ & $91(52.6)$ & $82(47.4)$ & 0.7 \\
\hline$\beta$-Blocker & $200(23.5)$ & $102(23.4)$ & $98(23.6)$ & 0.9 \\
\hline Diuretic & $240(28.2)$ & 145 (33.3) & $95(22.9)$ & 0.001 \\
\hline \multicolumn{5}{|c|}{ Laboratory analyses (mean \pm s.D.) } \\
\hline IGF1 $(\mu \mathrm{g} / \mathrm{l})$ & $79.1 \pm 27.9$ & $74.3 \pm 25.8$ & $84.1 \pm 29.2$ & $<0.001$ \\
\hline Creatinine $(\mu \mathrm{mol} / \mathrm{l})$ & $92.0 \pm 18.5$ & $86.1 \pm 16.9$ & $98.2 \pm 18.1$ & $<0.001$ \\
\hline NT-proBNP (ng/l) & $276.7 \pm 558.1$ & $284.6 \pm 642.6$ & $272.6 \pm 453.3$ & 0.7 \\
\hline $\mathrm{Hb}(\mathrm{g} / \mathrm{l})$ & $140.2 \pm 12.6$ & $136.1 \pm 11.2$ & $144.5 \pm 12.6$ & $<0.001$ \\
\hline
\end{tabular}

ACE, angiotensin converting enzyme; BMI, body mass index; BP, blood pressure; IGF1, insulin-like growth factor 1; ECG, electrocardiogram indicative of IHD; IHD, ischemic heart disease; NYHA, New York Heart Association functional class; $\mathrm{EF}$, ejection fraction; ASAT, serum aspartate aminotransferase; Hb, hemoglobin; NT-proBNP, N-terminal proBNP.

415). With regard to age, there was a small but significant difference between females and males $(P=0.002)$, females being older than males. With regard to the medical history, the male population had a higher prevalence of IHD than the female population $(P=0.03)$.

\section{IGF1 levels and characteristics of the study population}

Significantly higher levels of circulating IGF1 were found in males compared with females, $84.1 \pm 29.2$ vs $74.3 \pm 25.8 \mu \mathrm{g} / \mathrm{l}(P<0.001$; Table 1$)$. In the whole population, there was a significant correlation between IGF1 and weight $(P<0.001, r=0.1)$, height $(P<0.001$, $r=0.21)$, and serum creatinine $(P<0.001, r=0.1)$. In males, but not in females, we found a significant correlation between IGF1 regarding age $(P=0.006$, $r=-0.1)$, weight $(P<0.001, \quad r=0.2)$, height $(P=0.001, r=0.2)$, and BMI $(P=0.04, r=-0.1)$.

\section{IGF1 levels and treatment with ACE inhibitors}

Of all the 851 persons studied, 173 patients (20.3\%), 91 women $(52.6 \%)$ and 82 men $(47.4 \%)$, were treated with ACE inhibitors. Our results show that the patients on ACE inhibitors had significantly higher levels of IGF1 compared with those without ACE inhibitors,
$86.8 \pm 31.4$ vs $77.2 \pm 26.7 \mu \mathrm{g} / \mathrm{l} \quad(P<0.001)$. The difference in IGF1 values between the sexes was independent of treatment with ACE inhibitors.

IGF1 values were compared between the four systolic ventricular function classes according to $\mathrm{EF}$ defined as normal ( $\mathrm{EF}>50 \%$ ), mildly impaired ( $\mathrm{EF} 40-49 \%$ ), moderately impaired (EF 30-40\%), and severely impaired (EF <30\%) systolic function. In patients on ACE inhibitors, the highest values were found in class 3 $(92.9 \pm 41.9 \mu \mathrm{g} / \mathrm{l})$ compared with class 1 (78.2 $\pm 27.6 \mu \mathrm{g} / \mathrm{l} ; P=0.04)$.

Of the 851 participants, $42(5.0 \%)$ had an $\mathrm{EF}<40 \%$ and $765(93.4 \%)$ an $\mathrm{EF} \geq 40$. Among patients treated with ACE inhibitors, patients with an $\mathrm{EF}<40 \%$ had significantly higher IGF1 values compared with those with an $\mathrm{EF} \geq 40 \%(103.4 \pm 39.7$ vs $84.4 \pm 30.0 \mu \mathrm{g} / \mathrm{l}$; $P=0.02$; Table 2). There were also significantly higher IGF1 levels in those patients on ACE inhibitors who had higher proBNP levels in quartile 4 vs $1(93.2 \pm 35.3$ vs $78.7 \pm 28.8 \mu \mathrm{g} / \mathrm{l}$ respectively; $P=0.03$; Table 2 ).

Patients treated with ACE inhibitors and diagnosed with IHD by CAD history and ECG changes had higher IGF1 levels than those without CAD history and ECG changes characteristic for IHD $(100.1 \pm 34.7$ vs $80.5 \pm 28.1 \mu \mathrm{g} / \mathrm{l} ; P<0.001$; Table 2 ). For patients on ACE inhibitors, the highest IGF1 levels were found in patients with ECG changes characteristic for IHD compared with those without ECG changes 
Table 2 IGF1 levels in patients with heart failure (HF) or IHD with or without ACE inhibitor treatment (ACE-IT).

\begin{tabular}{|c|c|c|c|c|c|c|}
\hline \multirow[b]{2}{*}{ Disease/variables } & \multicolumn{2}{|c|}{ Without ACE-IT } & \multirow[b]{2}{*}{$P$ values } & \multicolumn{2}{|r|}{ With ACE-IT } & \multirow[b]{2}{*}{$P$ values } \\
\hline & $n$ & IGF1 & & $n$ & IGF1 & \\
\hline \multicolumn{7}{|l|}{ HF } \\
\hline $\mathrm{EF}(<40$ or $\geq 40 \%)$ & $25 / 647$ & $82.0 \pm 25.4 / 77.0 \pm 26.7$ & 0.4 & $17 / 146$ & $103.4 \pm 39.7 / 84.4 \pm 30.0$ & 0.02 \\
\hline \multicolumn{6}{|c|}{ IHD } & 0.03 \\
\hline ECG and CAD $(+/-)$ & $106 / 572$ & $74.9 \pm 27.8 / 77.6 \pm 27.2$ & 0.3 & $51 / 120$ & $100.1 \pm 34.7 / 80.5 \pm 28.1$ & $<0.001$ \\
\hline $\mathrm{ECG}(+/-)$ & $29 / 649$ & $79.1 \pm 17.4 / 77.2 \pm 27.0$ & 0.7 & $18 / 153$ & $115.7 \pm 27.1 / 82.9 \pm 30.1$ & $<0.001$ \\
\hline $\mathrm{CAD}(+/-)$ & $85 / 593$ & $73.3 \pm 24.7 / 77.7 \pm 26.8$ & 0.2 & $42 / 131$ & $98.4 \pm 35.0 / 83.6 \pm 29.8$ & 0.07 \\
\hline
\end{tabular}

$A C E$, angiotensin converting enzyme; q1/q4, quartile 1/quartile 4; CAD, coronary artery disease; ECG, electrocardiogram indicative of IHD; EF, ejection fraction; IGF1, insulin-like growth factor 1; IHD, ischemic heart disease; NT-proBNP, N-terminal proBNP.

$(115.7 \pm 27.1$ vs $82.9 \pm 30.1 \mu \mathrm{g} / \mathrm{l} ; \quad P<0.001)$. IGF 1 levels tended to be higher in patients on ACE inhibitors with a CAD history than in those without CAD history $(98.4 \pm 35.0$ vs $83.6 \pm 29.8 \mu \mathrm{g} / \mathrm{l} ; \quad P=0.07)$. No relationship was found between IGF1 levels and the presence of IHD in patients without ACE inhibitors.

In multivariate regression analyses with IGF1 as the dependent variable, gender, ACE inhibitors, and ECG indicative of IHD had a significant impact, whereas IHD, $\mathrm{EF}<40 \%$, creatinine, BMI, and proBNP were not significant (Table 3).

\section{IGF1 as a prognostic biomarker for CV mortality}

During the follow-up period of 8 years, the all-cause mortality was $27.0 \%(n=230$; Table 4$)$. In total, 134 (58.3\%) patients died of $\mathrm{CV}$ disease and 40 (17.4\%) died of malignant disease. IGF1 values for $\mathrm{CV}$ non-survivors $(83.7 \pm 30.0 \mu \mathrm{g} / \mathrm{l})$ were significantly higher than for those who survived the follow-up period (78.1 $\pm 27.4 \mu \mathrm{g} / \mathrm{l} ; P=0.034)$. All-cause mortality tended to be associated with increased IGF1 levels $(P=0.09)$.

IGF1 values were then divided into quintiles in order to compare mortality and $\mathrm{CV}$ mortality in groups with low and high IGFl levels (Table 5). The first and second quintiles were pooled, as well as the 4th and 5th and compared in between and to quintile 3. In order to assess the prognostic potential of IGF1, a univariate Cox proportional hazard regression analysis was used. The results indicated that the risk for $\mathrm{CV}$ mortality increased by $50 \%$ for participants with higher plasma IGF1 concentrations in the 4th and 5th quintiles compared with those in the 1st and 2nd quintiles $(P=0.03)$. A multivariate Cox proportional hazard regression analysis was then performed using a model including other well-known variables for CV mortality (Table 6). As shown in Table 6, high levels of IGF1 in the 4th and 5th quintiles compared with those in 1st and 2nd quintiles predicts a 1.6-fold increase in $\mathrm{CV}$ mortality $(P=0.03)$. Increased age had a 1.1-fold increase in risk for $\mathrm{CV}$ mortality $(P<0.001)$. For the patients with NYHA Class III HF, a 2.3-fold increase in risk for $\mathrm{CV}$ mortality was predicted $(P=0.001)$. For the patients with diabetes mellitus, 2.0-fold increase in risk for $\mathrm{CV}$ mortality was predicted $(P=0.001)$. We analyzed the relationship between $\mathrm{CV}$ mortality and NT-proBNP, considering $100 \mathrm{ng} / \mathrm{l}$ as a relevant physiological change in NT-proBNP, and obtained an hazard ratio (HR) for $\mathrm{CV}$ mortality of 1.06 (confidence interval (CI) $1.04-1.08, P<0.001)$. For creatinine, considering $20 \mu \mathrm{mol} / \mathrm{l}$ as a relevant physiological change, HR for CV mortality was 1.56 (1.35-1.79). We also examined the time-mortality relationship using Kaplan-Meier analysis, showing that the predictive value persists after 10 years (Fig. 1).

\section{Discussion}

In an elderly population with concomitant diseases representative for their age and followed for 8 years, we tested the possibility to use IGF1 as a biomarker for HF and IHD and as a predictor of CV mortality. Furthermore, the role of ACE inhibitors was found. All inhabitants aged $66-81$ years in the community were invited to participate and no participants were lost

Table 3 Multiple linear regression analyses with IGF1 as the dependent variable and age, gender, BMI, ACE inhibitors, ECG changes indicative of IHD, IHD, EF $<40 \%$, creatinine, and NT-proBNP as independent variables.

\begin{tabular}{|c|c|c|c|c|c|}
\hline \multirow[b]{2}{*}{ Variables } & \multirow[b]{2}{*}{ B } & \multirow[b]{2}{*}{ S.E.M. } & \multirow{2}{*}{$\begin{array}{c}P \\
\text { values }\end{array}$} & \multicolumn{2}{|c|}{$95 \% \mathrm{Cl}$ for $\mathrm{B}$} \\
\hline & & & & Lower & Upper \\
\hline Age (years) & -0.38 & 0.3 & 0.2 & -0.9 & 0.2 \\
\hline Gender & -8.4 & 2.04 & $<0.001$ & -12.4 & -4.4 \\
\hline BMI $\left(\mathrm{kg} / \mathrm{m}^{2}\right)$ & 0.2 & 0.2 & 0.3 & -0.2 & 0.7 \\
\hline $\mathrm{ACE}$ & -7.3 & 2.5 & 0.003 & -12.1 & -2.5 \\
\hline ECG & 11.2 & 4.8 & 0.02 & 1.7 & 20.6 \\
\hline$E F<40 \%$ & 5.0 & 4.7 & 0.3 & -4.3 & 14.2 \\
\hline IHD & -1.3 & 2.9 & 0.6 & -6.9 & 4.2 \\
\hline Creatinine $(\mu \mathrm{mol} / \mathrm{l})$ & 0.06 & 0.06 & 0.3 & -0.05 & 0.2 \\
\hline NT-proBNP (ng/l) & 0.001 & 0.002 & 0.6 & -0.003 & 0.005 \\
\hline
\end{tabular}

$\mathrm{ACE}$, angiotensin converting enzyme; $\mathrm{B}$, Cox regression coefficient, BMI, body mass index, $\mathrm{Cl}$, confidence interval; ECG, electrocardiogram changes indicative of IHD; EF, ejection fraction; IGF1, insulin-like growth factor 1; IHD, ischemic heart disease; NT-proBNP, N-terminal proBNP. 
Table 4 All-cause mortality, CV mortality, and malignancy mortality in the study population. Data are presented as $n(\%)$.

\begin{tabular}{lcccc}
\hline Mortality & $\begin{array}{c}\text { Whole } \\
\text { population }\end{array}$ & Female & Male & $\boldsymbol{P}$ values \\
\hline All cause & $230(27.0)$ & $98(42.6)$ & $132(57.4)$ & 0.002 \\
CV & $134(58.3)$ & $57(42.5)$ & $77(57.5)$ & 0.3 \\
Malignancy & $40(17.4)$ & $22(55.0)$ & $18(45.0)$ & 0.6 \\
\hline
\end{tabular}

during follow-up. Our results show that treatment with ACE inhibitors is associated with increased IGF1 levels, especially in patients with impaired cardiac function. High levels of IGF1 predict CV mortality independent of age and other known CV risk factors.

In this population, $20.3 \%$ of the participants were treated with ACE inhibitors and had significantly higher levels of IGF1 compared with those without ACE inhibitors. In the 'CHIANTI study' (19), which encompassed 745 subjects $\geq 65$ years of age, IGF1 levels were significantly higher in participants receiving ACE inhibitors compared with the rest of the study population. A 6-month treatment with fosinopril increased IGF1 levels in older adults with a high CV risk profile (18). Overall, there is strong evidence that ACE inhibitors lead to an increase in circulating IGF1 levels. We found significantly higher IGF 1 values in men than in women in accordance with a recent publication (24). The reason for this difference is not known but testosterone and also physical activity are known to affect IGFI $(24,25)$.

In our study, the most pronounced increase in IGF1 values was found between patients on ACE inhibitor treatment and an $\mathrm{EF}<40 \%$ and those with an $\mathrm{EF}$ $\geq 40 \%$. High levels of NT-proBNP, another well-known marker for HF, were only associated with raised IGF1 levels in patients on ACE inhibitors. When stratified according to EF, the highest IGF1 values were found in patients with an EF 30-40\%. Corbalan et al. (26), in a small, uncontrolled study on nine patients with HF NYHA Class III, reported that treatment with enalapril restored low IGF1 values and improved cardiac function. Andreassen et al. (27) reported increased IGF1 levels in patients treated with ACE inhibitors/ angiotensin II receptor blockers. However, they did not find a significant difference in IGF1 levels between patients with HF and controls.

When divided into those with and without ACE inhibitors, the increase in IGF1 levels in IHD was confined to those on ACE inhibitors $(P<0.001)$. Schneider et al. (3) have shown that high IGF1 levels are associated with CAD in women, but not in men. Patients with low IGF1 levels also showed increased risk for CAD. Kaplan et al. (28) failed to show a relationship between IGF1 and the risk for IHD in elderly subjects. The use of ACE inhibitors was not discussed in the above studies.
We found that persons with higher IGF1 levels in quintiles 4 and 5 compared to quintiles 1 and 2 had a $50 \%$ greater risk for dying of CV causes. This was still true after adjustment for age and other known CV risk factors: NYHA Class III, NT-proBNP, diabetes mellitus, BMI, creatinine, age, and gender (Table 6). A U-shaped association between CV mortality and low-normal and high-normal IGF1 levels was recently reported by Bunderen et al. (4). In this study, it should be noted that patients with prevalent CVD were excluded from cause-specific analysis of mortality. In another study, low IGF1 levels, below the 90th percentile, were associated with increased risk for all-cause mortality, CV mortality, and cancer mortality in men but not in women (29). Low IGF1 levels were associated with increased risk for fatal IHD among elderly subjects regardless of prevalent IHD and CVD risk factors (9). A recent population study in Australia, conducted on elderly men, failed to find a difference in CV mortality based on IGF1 levels according to quintiles (30).

In our study, there was a tendency toward an association between high IGF1 levels and all-cause mortality $(P=0.09)$. When comparing IGF1 levels according to quartiles, Andreassen et al. (6) found high plasma IGF1 levels to be independently associated with an increase in all-cause mortality. The association between circulating IGF 1 levels and all-cause mortality tended to be U-shaped, with increased mortality at both low and high IGF1 levels (6). In the study by Bunderen et al. (4) mentioned above, an increased risk for allcause mortality was found for elderly subjects with the lowest IGF1 levels in the 1st quintile compared with the 3rd quintile. Other studies have failed to show an association between IGF1 levels and all-cause mortality $(9,30-32)$. These conflicting results could be explained by differences in population age $(>17$ years in Saydah et al. (32), 51-89 years in Laughlin et al. (9) and $>65$ in Kaplan et al. (28), race, and unrecognized differences in lifestyle factors that modulate IGF levels. The impact of ACE inhibitors on CV and all-cause mortality was not taken into account in any of these studies.

To our knowledge, this observational study is the first to specifically address the effect of ACE inhibitors on IGF1 levels and HF, IHD, and CV mortality. Previous

Table 5 IGF1 quintiles and all-cause, CV, and malignancy mortality.

\begin{tabular}{lccllcc}
\hline & \multicolumn{2}{c}{ IGF1 } & & \multicolumn{3}{c}{ Mortality $(n(\%))$} \\
\cline { 1 - 3 } \cline { 5 - 7 } Quintile & $n$ & Mean \pm s.D. & & All cause & CV & Malignancy \\
\hline 1 & 169 & $45.7 \pm 8.2$ & & $39(16.9)$ & $21(15.7)$ & $8(20.0)$ \\
2 & 171 & $62.2 \pm 3.6$ & & $42(18.3)$ & $21(15.7)$ & $9(22.5)$ \\
3 & 171 & $74.8 \pm 3.6$ & & $48(20.9)$ & $26(19.4)$ & $8(20.0)$ \\
4 & 170 & $90.5 \pm 5.7$ & & $46(20.0)$ & $34(25.4)$ & $7(17.5)$ \\
5 & 170 & $122.0 \pm 19.7$ & & $55(23.9)$ & $32(23.9)$ & $8(20.0)$ \\
Total & 851 & & $230(100)$ & $134(100)$ & $40(100)$
\end{tabular}

avalues are expressed as $\mu \mathrm{g} / \mathrm{l}$. 
Table 6 Multivariate Cox proportional hazard regression analysis of prognostic power concerning cardiovascular mortality over 8-year follow-up period.

\begin{tabular}{|c|c|c|c|c|}
\hline \multirow[b]{2}{*}{ Variables } & \multirow{2}{*}{$\begin{array}{c}P \\
\text { values }\end{array}$} & \multirow[b]{2}{*}{ HR } & \multicolumn{2}{|c|}{ 95\% Cl for HR } \\
\hline & & & Lower & Upper \\
\hline Age (years) & $<0.001$ & 1.1 & 1.06 & 1.18 \\
\hline Gender & 0.07 & 0.7 & 0.5 & 1.03 \\
\hline ACE & 0.2 & 0.8 & 0.5 & 1.2 \\
\hline BMI $\left(\mathrm{kg} / \mathrm{m}^{2}\right)$ & 0.1 & 1.0 & 0.9 & 1.0 \\
\hline NYHA Class III & 0.001 & 2.3 & 1.4 & 3.9 \\
\hline DM & 0.001 & 2.0 & 1.4 & 3.1 \\
\hline IHD & 0.7 & 0.9 & 0.6 & 1.4 \\
\hline $\mathrm{Hb}(\mathrm{g} / \mathrm{l})$ & 0.2 & 1.0 & 1.0 & 1.0 \\
\hline Creatinine $(\mu \mathrm{mol} / \mathrm{l})$ & 0.02 & 1.01 & 1.001 & 1.019 \\
\hline $\begin{array}{l}\text { NT-proBNP (ng/l) } \\
\text { IGF1 }(\mu \mathrm{g} / \mathrm{l})\end{array}$ & 0.001 & 1.0 & 1.0 & 1.001 \\
\hline $\mathrm{Q} 1+\mathrm{Q} 2$ vs Q3 & 0.3 & 1.3 & 0.8 & 2.1 \\
\hline $\mathrm{Q} 1+\mathrm{Q} 2$ vs $\mathrm{Q} 4+\mathrm{Q} 5$ & 0.03 & 1.6 & 1.03 & 2.3 \\
\hline
\end{tabular}

$\mathrm{ACE}$, angiotensin converting enzyme; $\mathrm{BMI}$, body mass index; $\mathrm{Cl}$, confidence interval; DM, diabetes mellitus; $\mathrm{Hb}$, hemoglobin; HR, hazard ratio; IGF1, insulin-like growth factor 1; IHD, ischemic heart disease; NT-proBNP, $\mathrm{N}$-terminal proBNP; NYHA, New York Heart Association functional class

$\mathrm{Q}$, quintiles.

large population studies have not focused on this question $(19,27)$ and the few reports from small studies are difficult to interpret $(7,18)$. As described above, there are only two studies that have shown high IGF1 levels to be associated with all-cause mortality $(4,6)$ and CV mortality (4). Our results contradict the concept that high IGF1 levels are protective against atherosclerosis-associated cardiac events (2). Most previous studies have shown that low IGF1 levels correlate with

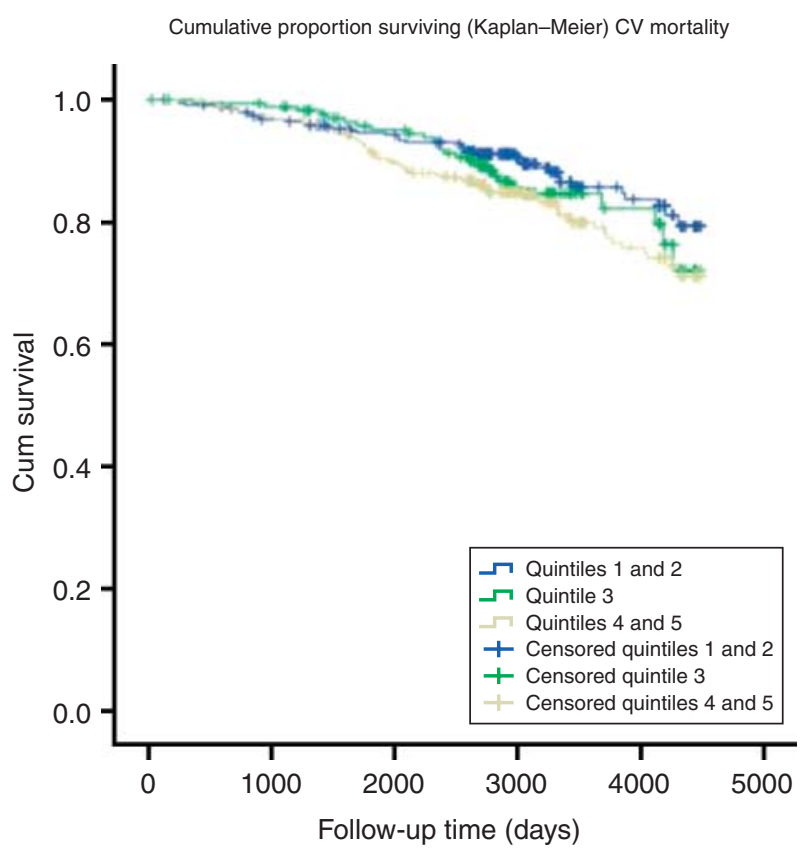

Figure 1 Kaplan-Meier analysis comparing IGF1 levels in quintiles 1 and 2 , quintile 3 , and quintiles 4 and 5 and cardiovascular mortality during a follow-up period of up to 8 years. increased CV and all-cause mortality (1, 2, 9, 33). We did not find any tendency toward increased mortality in subjects with low IGF1 values. It should be pointed out that we did not see the very low IGF1 values found in $\mathrm{GH}$-deficient patients reported to have increased CV mortality (33). However, population studies have also shown low IGF1 levels to be associated with increased CVD.

What can be extracted from our findings? One may speculate that low IGF1 levels have a protective role by increased resistance to oxidative stress associated with aging $(34,35)$. Experimental animal models have also shown an association between a deficit of IGF1 or nonfunctioning IGF1 and longer life span (36-38). These together with our results support the idea that there is a complex relationship between IGF1 levels and mortality and that a high IGF1 level could be a predictive biomarker for CV mortality.

The main strength of this population study is that the participants were recruited directly from the community without sampling, and every participant was followed over a long period of time up to 8 years $(7.9 \pm 2.6)$. No patient was lost during the follow-up. Nevertheless, this study has some limitations. One important limitation is the size of the study population, which resulted in the subgroups of individuals with an $\mathrm{EF}<40 \%$ being rather small. The results of comparisons between the subgroups should thus be interpreted with caution. Another limitation is the limited life span of study participants (66-81 years), which makes extrapolation of the results to other age groups unwise. Furthermore, we did not measure the interaction of IGF1 with IGFBPs, which can modulate free IGF1.

\section{Conclusion}

In this unique unselected population of elderly subjects from the community, we found that treatment with ACE inhibitors is associated with increased IGF1 levels, especially in patients with impaired cardiac function. High levels of IGF1 tend to be associated with an increased risk for $\mathrm{CV}$ mortality.

\section{Declaration of interest}

There is no conflict of interest that could be perceived as prejudicing the impartiality of the research report.

\section{Funding}

This work was supported by the County Council of Östergötland (LIO-19611, 2009; LIO-19641, 2009; LIO-45751, 2009; LIO131721, 2010; LIO-131411, 2010; LIO-60331, 2010).

\section{Acknowledgements}

We are grateful to Anna-Kristina Granath for excellent technical assistance. 


\section{References}

1 Juul A, Scheike T, Davidsen M, Gyllenborg J \& Jorgensen T. Low serum insulin-like growth factor-I is associated with increased risk of ischemic heart disease: a population-based case-control study. Circulation 2002106 939-944. (doi:10.1161/01.CIR. 0000027563.44593.CC)

2 Boquist S, Ruotolo G, Skoglund-Andersson C, Tang R, Björkegren J, Bond MG, de Faire U, Brismar K \& Hamsten A. Correlation of serum IGF-I and IGFBP-1 and -3 to cardiovascular risk indicators and early carotid atherosclerosis in healthy middle-aged men. Clinical Endocrinology 200868 51-58. (doi:10.1111/j.13652265.2007.02998.x)

3 Schneider HJ, Klotsche J, Saller B, Böhler S, Sievers C, Pittrow D, Ruf G, März W, Erwa W, Zeiher AM, Silber S, Lehnert H, Wittchen HU \& Stalla GK. Associations of age-dependent IGF-I SDS with cardiovascular diseases and risk conditions: crosssectional study in 6773 primary care patients. European Journal of Endocrinology 2008158 153-161. (doi:10.1530/EJE-07-0600)

4 Bunderen CC, van Nieuwpoort IC, van Schoor NM, Deeg DJ, Lips P \& Drent ML. The association of serum insulin-like growth factor-I with mortality, cardiovascular disease, and cancer in the elderly: a population-based study. Journal of Clinical Endocrinology and Metabolism 201095 4616-4624. (doi:10.1210/jc.2010-0940)

5 Fischer F, Schulte H, Mohan S, Tataru MC, Köhler E, Assmann G \& von Eckardstein A. Associations of insulin-like growth factors, insulin-like growth factor binding proteins and acid-labile subunit with coronary heart disease. Clinical Endocrinology 2004 61 595-602. (doi:10.1111/j.1365-2265.2004.02136.x)

6 Andreassen M, Raymond I, Kistorp C, Hildebrandt P, Faber J \& Kristensen LØ. IGF-1 as predictor of all cause mortality and cardiovascular disease in an elderly population. European Journal of Endocrinology 2009160 25-31. (doi:10.1530/EJE-08-0452)

7 Al-Obaidi MK, Hon JK, Stubbs PJ, Barnes J, Amersey RA, Dahdal M, Laycock JF, Noble MI \& Alaghband-Zadeh J. Plasma insulin-like growth factor-1 elevated in mild-to-moderate but not severe heart failure. American Heart Journal 2001142 E10. (doi:10.1067/mhj.2001.118116)

8 Spallarossa P, Brunelli C, Minuto F, Caruso D, Battistini M, Caponnetto S \& Cordera R. Insulin-like growth factor-I and angiographically documented coronary artery disease. American Journal of Cardiology 199677 200-202. (doi:10.1016/S00029149(96)90600-1)

9 Laughlin GA, Barrett-Connor E, Criqui MH \& Kritz-Silverstein D. The prospective association of serum insulin-like growth factor I (IGF-I) and IGF-binding protein-1 levels with all cause and cardiovascular disease mortality in older adults: the Rancho Bernardo Study. Journal of Clinical Endocrinology and Metabolism 200489 114-120. (doi:10.1210/jc.2003-030967)

10 Bayes-Genis A, Conover CA \& Schwartz RS. The insulin-like growth factor axis: a review of atherosclerosis and restenosis. Circulation Research 200086 125-130. (doi:10.1161/01.RES.86. 2.125)

11 Delafontaine P. Insulin-like growth factor I and its binding proteins in the cardiovascular system. Cardiovascular Research 199530 825-834. (doi:10.1016/S0008-6363(95)00163-8)

12 Ross J Jr \& Hongo M. The role of hypertrophy and growth factors in heart failure. Journal of Cardiac Failure 19962 (Supplement 4) S121-S128. (doi:10.1016/S1071-9164(96) 80067-4)

13 Donath MY, Jenni R, Brunner HP, Anrig M, Kohli S, Glatz Y \& Froesch ER. Cardiovascular and metabolic effects of insulin-like growth factor I at rest and during exercise in humans. Journal of Clinical Endocrinology and Metabolism 199681 4089-4094. (doi:10.1210/jc.81.11.4089)

14 Donath MY, Sütsch G, Yan XW, Piva B, Brunner HP, Glatz Y, Zapf J, Follath F, Froesch ER \& Kiowski W. Acute cardiovascular effects of insulin-like growth factor I in patients with chronic heart failure. Journal of Clinical Endocrinology and Metabolism $1998 \mathbf{8 3}$ 3177-3183. (doi:10.1210/jc.83.9.3177)
15 Tsukahara H, Gordienko DV, Tonshoff B, Gelato MC \& Goligorsky MS. Direct demonstration of insulin-like growth factor-I-induced nitric oxide production by endothelial cells. Kidney International 199445 598-604. (doi:10.1038/ki.1994. 78)

16 Muniyappa R, Walsh MF, Rangi JS, Zayas RM, Standley PR, Ram JL \& Sowers JR. Insulin-like growth factor 1 increases vascular smooth muscle nitric oxide production. Life Sciences 199761 925-931. (doi:10.1016/S0024-3205(97)00594-8)

17 Gustafsson T, Andersson P, Chen Y, Magnusson JO \& Arnqvist HJ. Interaction of angiotensin II and the insulin-like growth factor system in vascular smooth muscle cells. American Journal of Physiology 1999277 499-507.

18 Giovannini S, Cesari M, Marzetti E, Leeuwenburgh C, Maggio M \& Pahor M. Effects of ACE-inhibition on IGF-1 and IGFBP-3 concentrations in older adults with high cardiovascular risk profile. Journal of Nutrition, Health and Aging 20104 457-460. (doi:10.1007/s12603-010-0036-7)

19 Maggio M, Ceda GP, Lauretani F, Pahor M, Bandinelli S, Najjar SS, Ling SM, Basaria S, Ruggiero C, Valenti G \& Ferrucci L. Relation of angiotensin-converting enzyme inhibitor treatment to insulinlike growth factor-1 serum levels in subjects $>65$ years of age (the InCHIANTI study). American Journal of Cardiology 200697 1525-1529. (doi:10.1016/j.amjcard.2005.11.089)

20 Alehagen U, Ericsson A \& Dahlström U. Are there any significant differences between females and males in the management of heart failure? Gender aspects of an elderly population with symptoms associated with heart failure Journal of Cardiac Failure 200915 501-507. (doi:10.1016/j.cardfail.2009.01.010)

21 Karl J, Borgya A, Gallusser A, Huber E, Krueger K, Rollinger W \& Schenk J. Development of a novel, N-terminal-proBNP (NTproBNP) assay with a low detection limit. Scandinavian Journal of Clinical and Laboratory Investigation 1999230 177-181. (doi:10. 1080/00365519909168341)

22 Choy AM, Darbar D, Lang CC, Pringle TH, McNeill GP, Kennedy NS \& Struthers AD. Detection of left ventricular dysfunction after acute myocardial infarction: comparison of clinical, echocardiographic, and neurohormonal methods. British Heart Journal 1994 72 16-22. (doi:10.1136/hrt.72.1.16)

23 van Royen N, Jaffe CC, Krumholz HM, Johnson KM, Lynch PJ, Natale D, Atkinson P, Deman P \& Wackers FJ. Comparison and reproducibility of visual echocardiographic and quantitative radionuclide left ventricular ejection fractions. American Journal of Cardiology 199677 843-850. (doi:10.1016/S00029149(97)89179-5)

24 Jakobsdóttir S, van Nieuwpoort IC, Schaap LA, van Schoor NM, Lips P \& Drent ML. Serum insulin-like growth factor-I and body composition in community dwelling older people. Clinical Endocrinology 201073 173-180. (doi:10.1111/j.1365-2265. 2009.03747.x)

25 Muniyappa R, Sorkin JD, Veldhuis JD, Harman SM, Münzer T, Bhasin S \& Blackman MR. Long-term testosterone supplementation augments overnight growth hormone secretion in healthy older men. American Journal of Physiology. Endocrinology and Metabolism 2007293 E769-E775. (doi:10.1152/ajpendo. $00709.2006)$

26 Corbalan R, Acevedo M, Godoy I, Jalil J, Campusano C \& Klassen J. Enalapril restores depressed circulating insulin-like growth factor 1 in patients with chronic heart failure. Journal of Cardiac Failure 1998 4 115-119. (doi:10.1016/S1071-9164(98)90251-2)

27 Andreassen M, Kistorp C, Raymond I, Hildebrandt P, Gustafsson F, Kristensen LO \& Faber J. Plasma insulin-like growth factor I as predictor of progression and all cause mortality in chronic heart failure. Growth Hormone and IGF Research 200919 486-490. (doi:10.1016/j.ghir.2009.03.003)

28 Kaplan RC, McGinn AP, Pollak MN, Kuller LH, Strickler HD, Rohan TE, Cappola AR, Xue X \& Psaty BM. Association of total insulin-like growth factor-I, insulin-like growth factor binding protein-1 (IGFBP-1), and IGFBP-3 levels with incident coronary events and ischemic stroke. Journal of Clinical Endocrinology and Metabolism 200792 1319-1325. (doi:10.1210/jc.2006-1631) 
29 Friedrich N, Haring R, Nauck M, Lüdemann J, Rosskopf D, SpilckeLiss E, Felix SB, Dörr M, Brabant G, Völzke H \& Wallaschofski H. Mortality and serum insulin-like growth factor (IGF)-I and IGF binding protein 3 concentrations. Journal of Clinical Endocrinology and Metabolism 200994 1732-1739. (doi:10.1210/jc.2008-2138)

30 Yeap BB, Chubb SA, McCaul K, Ho KK, Hankey GJ, Norman PE \& Flicker L. Associations of insulin-like growth factor-I and its binding proteins 1 and 3 with all-cause and cardiovascular mortality in older men. The Health in Men Study. European Journal of Endocrinology 2011 164 715-723. (doi:10.1530/EJE-11-0059)

31 Kaplan RC, McGinn AP, Pollak MN, Kuller L, Strickler HD, Rohan TE, Cappola AR, Xue X \& Psaty BM. High insulin-like growth factor binding protein 1 level predicts incident congestive heart failure in the elderly. American Heart Journal $2008 \mathbf{1 5 5}$ 1006-1012. (doi:10.1016/j.ahj.2007.12.031)

32 Saydah S, Graubard B, Ballard-Barbash R \& Berrigan D. Insulin-like growth factors and subsequent risk of mortality in the United States. American Journal of Epidemiology $2007 \mathbf{1 6 6}$ 518-526. (doi:10.1093/aje/kwm124)

33 Rosén T \& Bengtsson BA. Premature mortality due to cardiovascular disease in hypopituitarism. Lancet 1990336 285-288. (doi:10.1016/0140-6736(90)91812-0)
34 Holzenberger M. The GH/IGF-I axis and longevity. European Journal of Endocrinology 2004151 (Supplement 1) S23-S27. (doi:10.1530/eje.0.151S023)

35 Laron Z. The GH-IGF1 axis and longevity. The paradigm of IGF1 deficiency. Hormones $2008724-27$.

36 Kimura KD, Tissenbaum HA, Liu Y \& Ruvkun G. Daf-2, an insulin receptor-like gene that regulates longevity and diapause in Caenorhabditis elegans. Science 1997277 942-946. (doi:10. 1126/science.277.5328.942)

37 Holzenberger M, Dupont J, Ducos B, Leneuve P, Géloën A, Even PC, Cervera P \& Le Bouc Y. IGF-I receptor regulaters life span and resistance to oxidative stress in mice. Nature $2003 \mathbf{4 2 1} 182-187$. (doi:10.1038/nature01298)

38 Brown-Borg HM, Borg KE, Meliska KJ \& Bartke A. Dwarf mice and the ageing process. Nature $1996 \mathbf{3 8 4} 33$. (doi:10.1038/ 384033a0)

Received 2 July 2011

Revised version received 25 September 2011

Accepted 5 October 2011 